\title{
Survivin downregulation by siRNA sensitizes human hepatoma cells to TRAIL-induced apoptosis
}

\author{
KAZUHIKO NAKAO ${ }^{1}$, KEISUKE HAMASAKI ${ }^{2}$, TATSUKI ICHIKAWA ${ }^{2}$, KAZUHIKO ARIMA ${ }^{2}$, \\ KATSUMI EGUCHI $^{2}$ and NOBUKO ISHII ${ }^{1}$ \\ ${ }^{1}$ Health Research Center, Nagasaki University, 1-7-1, Sakamoto; ${ }^{2}$ First Department of Internal Medicine, \\ Nagasaki University School of Medicine, 1-7-1, Sakamoto, Nagasaki 852-8501, Japan
}

Received December 2, 2005; Accepted January 23, 2006

\begin{abstract}
Survivin, an anti-apoptotic protein, is abundantly expressed in a variety of cancer cells, including hepatoma cells, resulting in the resistance of these cells to various apoptotic stimuli. Tumor necrosis factor (TNF)-related apoptosis-inducing ligand (TRAIL) is known to induce cancer cell-specific apoptosis, but hepatoma cells are resistant to TRAIL-induced apoptosis. In the present study, we have examined whether the downregulation of survivin by short interfering RNA (siRNA) promotes spontaneous or TRAILinduced apoptosis in Huh-7 human hepatoma cells. Survivin siRNA transfection downregulated the expression of survivin in Huh- 7 cells and reduced cell viability by $20 \%$ through inducing spontaneous apoptosis. TRAIL (1 to $2 \mathrm{ng} / \mathrm{ml}$ ) only slightly induced apoptosis in Huh-7 cells; however, survivin siRNA transfection apparently enhanced TRAIL-induced apoptosis. These results suggest that the level of survivin is linked to the susceptibility of Huh-7 cells to TRAIL. It is possible that survivin downregulation by siRNA combined with TRAIL administration may provide a new therapeutic strategy against hepatoma.
\end{abstract}

\section{Introduction}

Survivin, the smallest mammalian member of the inhibitor of apoptosis (IAP) family, plays a key role, not only in cell division but also in apoptosis inhibition, by repressing caspase activities (1-3). Survivin is abundantly expressed in a variety of cancer cells, including hepatoma cells, but not in normal cells (3-6), resulting in the resistance of cancer cells to various apoptotic stimuli $(3,5,7,8)$. In addition, the overexpression of survivin in cancer is closely related to unfavorable disease

Correspondence to: Dr Kazuhiko Nakao, Health Research Center, Nagasaki University, 1-7-1, Sakamoto, Nagasaki 852-8501, Japan

E-mail: kazuhiko@net.nagasaki-u.ac.jp

Key words: survivin, siRNA, tumor necrosis factor-related apoptosis-inducing ligand, hepatoma outcome $(3,6,9-11)$. Therefore, survivin is a possible target of cancer therapy. In fact, the downregulation of survivin by anti-sense oligonucleotides, short interfering RNA (siRNA) and dominant-negative mutant induces apoptosis of cancer cells or sensitizes cancer cells to chemotherapeutic agents and irradiation (12).

Tumor necrosis factor (TNF)-related apoptosis-inducing ligand (TRAIL), a member of the TNF superfamily, induces apoptosis in a variety of cancer cells with little or no effect on normal cells $(13,14)$. However, several cancer cells, including hepatoma cells, are resistant to TRAIL-induced apoptosis (15). Griffith et al have reported that the cellular level of survivin is linked to the resistance against TRAIL-induced apoptosis of renal cell carcinoma cells (16). It has been also reported that the downregulation of survivin by siRNA sensitizes resistant melanoma cells to TRAIL-induced apoptosis (17). Moreover, we previously reported that interferon (IFN)- $\alpha$ downregulated the survivin expression in human hepatoma cells and sensitized these cells to TRAIL-induced apoptosis, and ectopic expression of survivin partially rescued these cells from IFN- $\alpha$ TRAILinduced apoptosis (18). Therefore, it is possible that survivin plays a role in the resistance to TRAIL-induced apoptosis in human hepatoma cells. To confirm this, in the present study, we examined whether downregulation of survivin by siRNA can sensitize human hepatoma cells to TRAIL-induced apoptosis.

\section{Materials and methods}

siRNAs. To select siRNA duplexes for survivin mRNA, we searched for sequences of AA and the N19 (N, any nucleotide) from the open reading frame of human survivin as described previously (19). siRNAs with the following sequences were used for experiments: surA, 5'-GGUUAAUUCUUCAAA CUGCTT-3' (antisense); surB, 5'-GCAAUUUUGUUCUUG GCUCTT-3' (antisense).

siRNA against green fluorescent protein (GFP) was also used as a control: siGFP, 5'-UGCGCUCCUGGACGUAGC CTT-3' (antisense). All siRNAs were purchased from Nihon Bioservice (Saitama, Japan).

Cell culture and transfection. Huh-7 human hepatoma cells were maintained in RPMI with 5\% fetal bovine serum. Cells were plated on a 96-well plate or Lab-Tek chamber slide at 


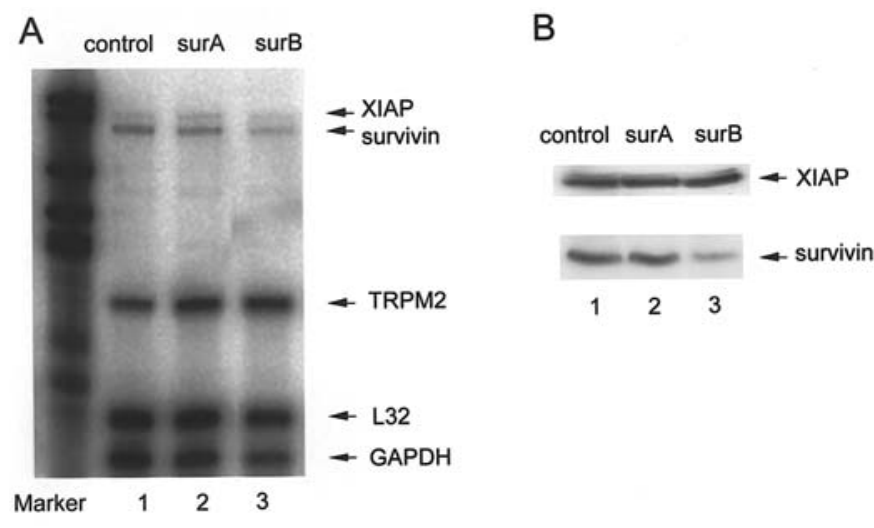

Figure 1. Effect of siRNA transfection on survivin expression in Huh-7 cells. Huh-7 cells were transfected with siGFP as a control (lane 1), surA (lane 2) or surB (lane 3), respectively. (A) The levels of indicated mRNAs were analyzed by RNase protection assay. (B) The expression of XIAP and survivin was analyzed by Western blotting. Results are from one representative experiment from a total of three performed.

an appropriate density. A day later, cells were transfected with each siRNA (4 pmol/10 4 cells) using oligofectamine (Gibco-Invitrogen, Rockville, MD, USA) according to the instructions provided by the manufacturer. The medium was replaced with fresh medium $6 \mathrm{~h}$ after transfection, and the cells were cultured for $36 \mathrm{~h}$ and treated with or without varying concentrations of TRAIL for $12 \mathrm{~h}$.

RNase protection assay. The RNase protection assay was performed using a RiboQuant Multi-Probe RNase Protection Assay System (BD PharMingen, Franklin Lakes, NJ, USA). According to the instructions provided by the manufacturer, an hAPO5c (inhibitors of apoptosis) template set, including an L32 ribosomal protein and a glyceraldehyde-3-phosphate dehydrogenase (GAPDH) template as internal controls, was labeled with $\left[\alpha^{32} \mathrm{P}\right]-\mathrm{UTP}$ using T7 RNA polymerase. The labeled RNA probes were hybridized with $10 \mu \mathrm{g}$ of total RNA from Huh-7 cells transfected with each siRNA. Samples were digested with RNase to remove single-stranded (nonhybridized) RNA. The remaining probes were resolved on $6 \%$ urea-polyacrylamide-bis-acrylamide gels. Gels were dried and analyzed using an image analyzer (BAS; Fuji Film Co., Tokyo, Japan).

Western blot analysis. Cells were lysed by adding lysis buffer (50 mM Tris [pH 8.0], $150 \mathrm{mM} \mathrm{NaCl,} \mathrm{0.1 \%} \mathrm{SDS,} \mathrm{1 \%} \mathrm{NP40}$ and $100 \mu \mathrm{g} / \mathrm{ml} \mathrm{PMSF}$ ) for $10 \mathrm{~min}$ at $4^{\circ} \mathrm{C}$ and passed several times through a 25-gauge needle. The same amount of protein from each lysate $(20 \mu \mathrm{g} /$ well) was subjected to $12 \%$ SDS-PAGE. Proteins were transferred onto nitrocellulose membranes that were then blocked for $1.5 \mathrm{~h}$ using $5 \%$ nonfat dried milk in PBS containing 0.1\% Tween-20 (PBS-T), washed with PBS-T and incubated at room temperature for $1 \mathrm{~h}$ in the presence of each antibody (mouse monoclonal antihuman XIAP from MBL, Nagoya, Japan; and rabbit polyclonal anti-human survivin from Alpha Diagnostic International Inc., San Antonio, TX, USA). The membranes were washed with PBS-T and incubated with horseradish peroxidase-conjugated anti-rabbit IgG or anti-mouse IgG for $1 \mathrm{~h}$. Following washing with PBS-T, immunoreactive bands were visualized using the

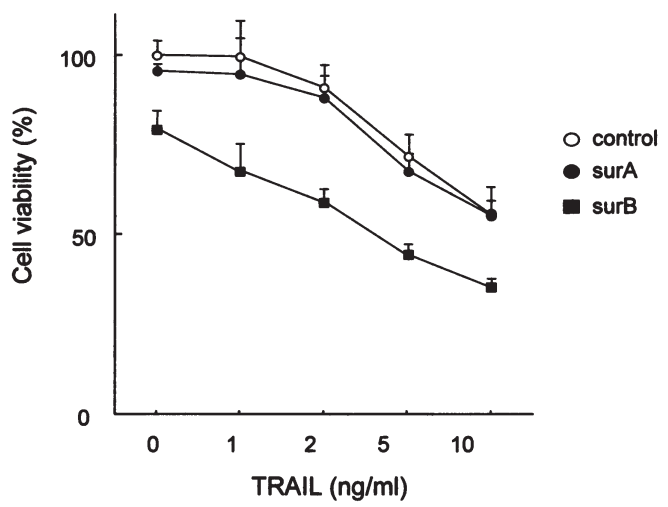

Figure 2. Effect of siRNA transfection with or without TRAIL on the viability of Huh-7 cells. Huh-7 cells were transfected with siGFP as a control (०), surA $(\bullet)$ or surB $(\bullet)$, respectively, and then treated with various concentrations of TRAIL for $12 \mathrm{~h}$. Cell viability was determined by the colorimetric method. Data represent mean \pm SD values of the four experiments.

ECL chemiluminescence system (Amersham Life Science, Buckinghamshire, UK).

Analysis of cell viability and apoptosis. Cell viability was determined by the colorimetric method using a Cell Counting kit (Wako Life Science, Osaka, Japan). The absorbance of each well was measured at $405 \mathrm{~nm}$ with a microtiter plate reader (Multiskan JX; Thermo BioAnalysis Co., Tokyo, Japan). For the detection of apoptosis, TUNEL assay was performed using a DeadEnd ${ }^{\mathrm{TM}}$ Fluorometric TUNEL System (Promega, Madison, WI, USA). Briefly, the cells cultured in Lab-Tek chamber slides were fixed in $4 \%$ paraformaldehyde in PBS. The fragmented DNA of apoptotic cells was detected by catalytically incorporating fluorescein-12-dUTP at 3'-OH DNA ends using the terminal deoxynucleotidyl transferase. $1 \mu \mathrm{g} / \mathrm{ml}$ of propidium iodide (PI) was added for nuclear staining. Sample slides were directly visualized by fluorescence microscopy (BX 50; Olympus, Tokyo, Japan) at $520 \mathrm{~nm}$ for the green fluorescence of fluorescein and at $>620 \mathrm{~nm}$ for the red fluorescence of PI.

\section{Results}

siRNA transfection downregulates survivin expression. To confirm that siRNA transfection downregulates survivin expression in Huh-7 cells, RNase protection assay and Western blotting were performed (Fig. 1). surA transfection did not repress the level of survivin mRNA, but slightly upregulated the level of XIAP mRNA. In contrast, surB transfection repressed the level of survivin mRNA, but did not upregulate the level of XIAP mRNA (Fig. 1A). The levels of TRPM2, L32 and GAPDH mRNAs were almost unchanged by the transfection of surA and surB. Similarly, surB transfection clearly repressed survivin expression, but did not repress XIAP expression (Fig. 1B).

Survivin downregulation by siRNA enhances TRAIL-mediated cytotoxicity. We examined the effect of survivin siRNA transfection with or without TRAIL on cell viability (Fig. 2). surB transfection alone repressed the viability of Huh-7 cells by almost $20 \%$ compared with the control but surA transfection 


\section{A control}

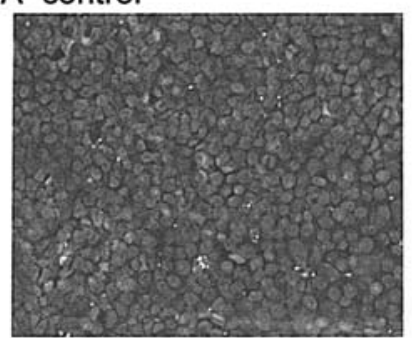

C TRAIL $(2 \mathrm{ng} / \mathrm{ml})$

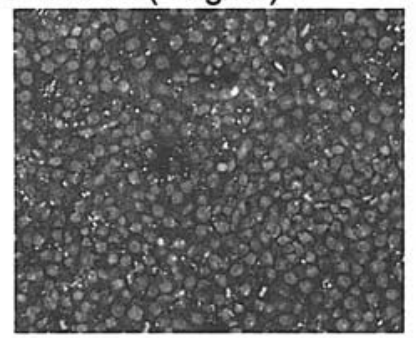

B surB
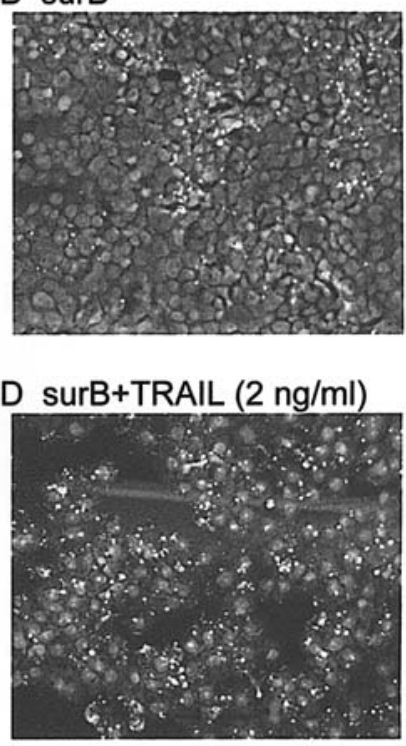

Figure 3. Effect of siRNA transfection with or without TRAIL on apoptosis in Huh-7 cells. Huh-7 cells were transfected with (A) siGFP alone as a control, (B) suB alone, (C) siGFP followed by TRAIL $(2 \mathrm{ng} / \mathrm{ml})$ treatment and (D) surB followed by TRAIL ( $2 \mathrm{ng} / \mathrm{ml})$ treatment. Apoptotic cells were detected by TUNEL assay. Results are from one representative experiment from a total of four performed.

did not. Low concentrations of TRAIL ( 1 and $2 \mathrm{ng} / \mathrm{ml}$ ) showed little effect on the viability of control cells, although high concentrations of TRAIL ( 5 and $10 \mathrm{ng} / \mathrm{ml}$ ) reduced the viability. On the other hand, surB transfection sensitized Huh-7 cells to TRAIL-mediated cytotoxicity. In fact, the viability of cells transfected with surB and treated with TRAIL ( 1 or $2 \mathrm{ng} / \mathrm{ml}$ ) was nearly equal to the viability of control cells treated with TRAIL ( 5 or $10 \mathrm{ng} / \mathrm{ml}$ ), respectively.

Survivin downregulation by siRNA enhances TRAIL-induced apoptosis. To clarify whether surB transfection enhances TRAIL-induced apoptosis in Huh-7 cells, TUNEL assay was performed (Fig. 3). TUNEL-positive nuclei, small and bright fluorescence spots, were scattered in the cells either transfected with surB or treated with TRAIL ( $2 \mathrm{ng} / \mathrm{ml})$, respectively. However, TUNEL-positive nuclei were apparently increased by combination of surB transfection with TRAIL treatment.

\section{Discussion}

We previously reported that IFN- $\alpha$ sensitized Huh-7 cells to TRAIL-induced apoptosis, in which IFN- $\alpha$ not only reduced survivin expression but also inhibited $N F-\kappa B$ activity and increased the expression of DR5, a death receptor of TRAIL (18). However, we could not address which was the key change directly relevant to the susceptibility to TRAIL, although ectopic expression of survivin partially rescued the IFN- $\alpha$ /TRAIL-induced apoptosis. In the present study, the downregulation of survivin by siRNA transfection sensitized Huh-7 cells to TRAIL-induced apoptosis as well as IFN- $\alpha$, suggesting that downregulation of survivin is the major cause of IFN- $\alpha$-mediated susceptibility of Huh-7 cells to TRAIL. Therefore, it is possible that the level of survivin is linked to the resistance against TRAIL-induced apoptosis in Huh-7 cells. This is consistent with previous observations in renal cell carcinoma cells and melanoma cells $(16,17)$.

In this study, downregulation of survivin reduced the viability of Huh-7 cells through the induction of apoptosis. It was reported that an adenovirus expressing the dominant negative mutant of survivin caused spontaneous apoptosis in human cell lines of breast, cervical, prostate, lung and colorectal cancer but did not affect the viability of normal human cells, including fibroblasts, endothelium or smooth muscle cells $(12,20)$. It was also reported that transduction of antisense oligonucleotides and siRNA against survivin induced apoptosis in HepG2 (21) and SMMC-7721 (22) human hepatoma cells, respectively. Therefore, it is likely that survivin supports the survival of hepatoma cells through inhibiting spontaneous apoptosis.

Survivin is abundantly expressed in hepatoma cells but not in normal hepatocytes $(5,6)$, and TRAIL specifically induces apoptosis in cancer cells but not in normal hepatocytes $(13,14)$. Therefore, the combination therapy of survivin knockdown and TRAIL administration may provide a new strategy for hepatoma treatment.

\section{References}

1. Li F, Ackermann EJ, Bennett CF, Rothermel AL, Plescia J, Tognin S, Villa A, Marchisio PC and Altieri DC: Pleiotropic cell-division defects and apoptosis induced by interference with survivin function. Nat Cell Biol 1: 461-466, 1999.

2. Altieri DC: Validating survivin as a cancer therapeutic target. Nat Rev Cancer 3: 46-54, 2003.

3. Altieri DC: Survivin, versatile modulation of cell division and apoptosis in cancer. Oncogene 22: 8581-8589, 2003.

4. Ambrosini G, Adida C and Altieri DC: A novel anti-apoptosis gene, survivin, expressed in cancer and lymphoma. Nat Med 3: 917-921, 1997.

5. Ito T, Shiraki K, Sugimoto K, Yamanaka T, Fujikawa K, Ito M, Takase K, Moriyama M, Kawano H, Hayashida M, Nakano T and Suzuki A: Survivin promotes cell proliferation in human hepatocellular carcinoma. Hepatology 31: 1080-1085, 2000.

6. Ikeguchi M, Hirooka Y and Kaibara N: Quantitative analysis of apoptosis-related gene expression in hepatocellular carcinoma. Cancer 95: 1938-1945, 2002.

7. Tamm I, Wang Y, Sausville E, Scudiero DA, Vigna N, Oltersdorf $\mathrm{T}$ and Reed JC: IAP-family protein survivin inhibits caspase activity and apoptosis induced by Fas (CD95), Bax, caspases, and anticancer drugs. Cancer Res 58: 5315-5320, 1998.

8. Rodel F, Hoffmann J, Distel L, Herrmann M, Noisternig T, Papadopoulos T, Sauer R and Rodel C: Survivin as a radioresistance factor, and prognostic and therapeutic target for radiotherapy in rectal cancer. Cancer Res 65: 4881-4887, 2005.

9. Kawasaki H, Altieri DC, Lu CD, Toyoda M, Tenjo T and Tanigawa N: Inhibition of apoptosis by survivin predicts shorter survival rates in colorectal cancer. Cancer Res 58: 5071-5074, 1998.

10. Tamm I, Richter S, Oltersdorf D, Creutzig U, Harbott J, Scholz F, Karawajew L, Ludwig WD and Wuchter C: High expression levels of $\mathrm{x}$-linked inhibitor of apoptosis protein and survivin correlate with poor overall survival in childhood de novo acute myeloid leukemia. Clin Cancer Res 10: 3737-3744, 2004.

11. Shinohara ET, Gonzalez A, Massion PP, Chen H, Li M, Freyer AS, Olson SJ, Andersen JJ, Shyr Y, Carbone DP, Johnson DH, Hallahan DE and Lu B: Nuclear survivin predicts recurrence and poor survival in patients with resected nonsmall cell lung carcinoma. Cancer 103: 1685-1692, 2005.

12. Zaffaroni N, Pennati M and Daidone MG: Survivin as a target for new anticancer interventions. J Cell Mol Med 9: 360-372, 2005.

13. Walczak H, Miller RE, Ariail K, Gliniak B, Griffith TS, Kubin M, Chin W, Jones J, Woodward A, Le T, Smith C, Smolak P, Goodwin RG, Rauch CT, Schuh JC and Lynch DH: Tumoricidal activity of tumor necrosis factor-related apoptosis-inducing ligand in vivo. Nat Med 5: 157-163, 1999. 
14. Lawrence D, Shahrokh Z, Marsters S, Achilles K, Shih D, Mounho B, Hillan K, Totpal K, DeForge L, Schow P, Hooley J, Sherwood S, Pai R, Leung S, Khan L, Gliniak B, Bussiere J, Smith CA, Strom SS, Kelley S, Fox JA, Thomas D and Ashkenazi A: Differential hepatocyte toxicity of recombinant Apo2L/TRAIL versions. Nat Med 7: 383-385, 2001.

15. Yamanaka T, Shiraki K, Sugimoto K, Ito T, Fujikawa K, Ito M, Takase K, Moriyama M, Nakano T and Suzuki A: Chemotherapeutic agents augment TRAIL-induced apoptosis in human hepatocellular carcinoma cell lines. Hepatology 32: 482-490, 2000.

16. Griffith TS, Fialkov JM, Scott DL, Azuhata T, Williams RD, Wall NR, Altieri DC and Sandler AD: Induction and regulation of tumor necrosis factor-related apoptosis-inducing ligand/Apo-2 ligand-mediated apoptosis in renal cell carcinoma. Cancer Res 62: 3093-3099, 2002.

17. Chawla-Sarkar M, Bae SI, Reu FJ, Jacobs BS, Lindner DJ and Borden EC: Downregulation of Bcl-2, FLIP or IAPs (XIAP and survivin) by siRNAs sensitizes resistant melanoma cells to Apo2L/TRAIL-induced apoptosis. Cell Death Differ 11: 915-923, 2004.
18. Shigeno M, Nakao K, Ichikawa T, Suzuki K, Kawakami A, Abiru S, Miyazoe S, Nakagawa Y, Ishikawa H, Hamasaki K, Nakata K, Ishii N and Eguchi K: Interferon-alpha sensitizes human hepatoma cells to TRAIL-induced apoptosis through DR5 upregulation and NF-kappa B inactivation. Oncogene 22: 1653-1662, 2003.

19. Hamasaki K, Nakao K, Matsumoto K, Ichikawa T, Ishikawa $H$ and Eguchi K: Short interfering RNA-directed inhibition of hepatitis B virus replication. FEBS Lett 543: 51-54, 2003.

20. Mesri M, Wall NR, Li J, Kim RW and Altieri DC: Cancer gene therapy using a survivin mutant adenovirus. J Clin Invest 108: 981-990, 2001.

21. Dai DJ, Lu CD, Lai RY, Guo JM, Meng H, Chen WS and Gu J: Survivin antisense compound inhibits proliferation and promotes apoptosis in liver cancer cells. World J Gastroenterol 11: 193-199, 2005.

22. Cheng SQ, Wang WL, Yan W, Li QL, Wang L and Wang WY: Knockdown of survivin gene expression by RNAi induces apoptosis in human hepatocellular carcinoma cell line SMMC7721. World J Gastroenterol 11: 756-759, 2005. 